\title{
A pathway to involve consumers for exchanging electronic waste: a deep learning integration of structural equation modelling and artificial neural network
}

\author{
Arsalan Najmi ${ }^{1} \cdot$ Kanagi Kanapathy $^{1}{ }^{\mathbb{D}} \cdot$ Azmin Azliza Aziz $^{1}$
}

Received: 26 April 2021 / Accepted: 11 November 2021 / Published online: 24 November 2021

○) Springer Japan KK, part of Springer Nature 2021

\begin{abstract}
The pandemic of COVID-19 has disrupted every human life by putting the global activities at halt. In such a situation, people while staying at home tend to have an increased consumption which also leads to an increased level of waste generation. The case of electronic waste is also not different; however, it has severe repercussions while comparing it with other general household wastes. The application of reverse logistics by the manufacturers though serve the purpose but its success is highly dependent on the participation of the consumers. Hence, the present study is an attempt to gauge the level of participation of the consumers in the reverse exchange programs. Because of the predictability limitations of the typical StructuralEquation-Modelling models, the present study employs the deep learning of the dual-staged partial least squares-structural equation modelling artificial neural network approach. The findings of the study confirms the individual's attitude as the most significant determinant of the intention to exchange, followed by level of awareness and norms, whereas perceived behavior control was found to be least important though significant. Based on these findings, the manufacturers have been recommended to improve the consumers' involvement in reverse exchange programs, whereas government institutions are also recommended to encourage public-private partnerships in channelizing the product returns.
\end{abstract}

Keywords Reverse exchange - Theory of planned behavior · Partial least squares-structural equation modelling · Artificial neural network $\cdot$ Deep learning $\cdot$ Electronic waste

\section{Introduction}

Despite having an antagonistic relationship of the recent pandemic "COVID-19" with the human life which has affected every single individual, it is found to be favorable and friendly for the environment because of pollution prevention [1]. During the imposed lockdown, individuals were forced to stay at home, which led to an increased consumption but it also significantly disturbed the cycle of waste management [2]. This is because of fewer personnel and/

Kanagi Kanapathy

kanagik@um.edu.my

Arsalan Najmi

arsalan-najmi@hotmail.com

Azmin Azliza Aziz

aazliza@um.edu.my

1 Faculty of Business and Accountancy, University of Malaya, 50603 Kuala Lumpur, Malaysia or services available for the collection of waste. Moreover, while staying at home people also had de-cluttering which led to the removal of unnecessary items, however, their purpose is not fulfilled as the waste from their doorstep is not timely collected [3].

The term waste has been explained as anything which does not possess any further utility for the owner and needs to be thrown away [4]. The general household waste comprised several things including paper and glass, etc., which can easily be recycled; however, other materials like plastics are difficult to recycle and are one of the major factors of environment pollution which could take years to decompose $[5,6]$. It has been estimated by the World Bank that the annual levels of the household waste globally is expected to reach 2.2 billion metric tons which is a serious challenge to the government municipal bodies and authorities worldwide.

Comparatively, the electronic waste or e-waste and its subsequent management is more noxious and dangerous because of the emission of methane and hence needs to managed with due diligence [7]. This is because of the 
substance in e-wastes not only include plastic but also include chromium, lead, mercury and arsenic and hence require state-of-the-art infrastructure for further processing it without directly dumping it in landfills to dilute its impact on the environment $[8,9]$. Thus improper waste management will further devastate the habitat and ecology [8].

In such a situation, an important aspect and/or solution could be reverse logistics (RL), which can provide assistance in the management of waste in general and e-waste in particular. Precisely, RL is a setting which is deployed to bring back the products either within the useful life or when it reaches its end of life (EOL) with an objective to re-use, recycle, resell and/or dispose it [12]. In this setting, the roles of the parties are also switched as the customer acts as the supplier of the products since they are at the supply side of the products and vice versa [13].

It is noteworthy to mention that the annual consumption volume of the electronic equipment is increasing by 2.5 million tons annually which makes the role of consumers crucial [10]. Though by 2030, it has been targeted to reduce the waste generation by sustainable consumption substantially through reducing, reusing, and recycling, whereas recent emphasis is also being given to the option of donating and reselling, however, the alternate option of exchanging EOL products or e-wastes and its potential to safeguard the habitat is being ignored.

Conventionally, the option of exchange is exercised when the products are not found in accordance with the description provided by either seller or buyer. However, in the situation where technology of recycling is comparatively expensive [14] for the external parties to invest for the purpose of revenue generation, calling back and disposing of the waste is termed as the manufacturer's extended responsibility, whereas providing an option to the consumer at the product's EOL could also lead to several potential benefits to the manufacturers [15]. These benefits include fulfilment of manufacturer's extended responsibility, retaining the consumers as by this option the existing consumers can be offered the latest products by the same manufacturers and most importantly in re-utilizing the existing components or it's parts, with no or litter modification and improvement [16]. Altogether, by the option of exchange, sustainable consumption and production is more likely to achieve and hence need to be carefully considered by both consumers and manufacturers.

Consumers being supplier in the RL settings, are generally not aware of the threat which it may cause to the environment if they do not de-clutter the e-waste in time whereas consumers reportedly do not dispose the e-waste deliberately [17]. Consumers need to make the products available to the manufacturers so that they can be brought back into the RL settings, whereas manufacturers need to provide multiple alternatives to the consumers to motivate them for reversing the products [15].

The literature related to RL myopically revolves around business to business settings. However, exploring the consumer side which in fact is the starting point of the product in such a setting, is very limited. Furthermore, of this limited number, the major portion has studied only the recycling side whereas there are few studies that has discussed different options including donating and reselling, returning and disposing. Considering the reverse exchange from consumers side of e-waste, the only study was found in recent is of Yuan et al. [18], however, this study has only studied limited motivating factors of the reverse exchange whereas there are certain other important factors which can make consumers motivate their decision on the reverse exchange.

In addition to the aforementioned shortcomings, researches employing survey data have used regressionbased techniques, including multiple regression and structural equation modelling (SEM) for hypotheses testing. The present study is intended to address these shortcomings. For estimating, the present study has employed an artificial intelligence based deep machine learning technique named artificial neural network (ANN). Moreover, the present study employs deep learning technique as suggested by Lee et al. [19], which is capable of offering more insights as compared to conventional ANN. Nevertheless based on the findings, this study will offer some robust insights to the stakeholders in their offering of reverse exchange.

The remainder of the research discusses the literature review in the next section, following methodology and statistical estimations, whereas the last sections comprise discussion, conclusion, and recommendations.

\section{Literature review}

\section{Theoretical background}

Predicting a human behavior has always been arduous for theorists, researchers and practitioners. Assuredly the utilization of Theory of Planned Behavior (TPB) [20] is parsimonious when it comes to the prediction of human behavior. TPB being an upgraded version of Theory of Reasoned Action (TRA) [21] predicts human behavioral intention as the product of three essential elements namely: Attitude (ATT), Subjective Norms (SBN) and Perceived Behavioral Control (PBC).

In the context of RL, the application of TPB has generated almost consistent and robust framework in the prediction of individual's behavior. Though there are some other models which have also been studied in RL settings includes Value-Belief-Norm (VBN) theory by Stern [22] in predicting reverse exchange [18] and Norm activation model by 
Schwartz [23] in predicting recycling [24]. However, these models have limited determinants of predicting behavioral intention, thus making the selection of TPB a better choice for predicting reverse exchange in the present study. Moreover, the application of TPB has been documented, across various RL behavioral practices including recycling [15], returning [16], reselling, disposing and donating [5] etc. The present study also expands the TPB with other constructs including Awareness of Consequences (AC) and Moral Norms (MN) which were adapted from Schwartz's [23] model of altruistic behavior. The relationships between the constructs are discussed in the subsequent sub-sections.

\section{Development of hypotheses}

\section{Attitude and intention to exchange}

Attitude (ATT), is referred as an individual's perceived favorable or unfavorable beliefs relating to a certain task or act, which will either motivate or create resistance in performing that particular task or act [25]. An individual with a positive ATT towards a certain behavior is more likely to perform it and vice versa. Though ATT is reportedly found to be a strong predictor of behavioral intention, however, its strength and significance is still contentious precisely in the pro-environmental studies. For instance, while purchasing a remanufactured product, its relationship was found significant [26], so as with the reusing behavior, however, for reselling, it was insignificant [11]. Precisely in the RL practices, for returning the EOL product it was reported to have significant relationship [16] as well as insignificant [27], whereas for recycling it has also been reported as significant [15] and insignificant [5]. Considering the relationship for reverse exchange, though it was found to be significant by [18], however, there is a need to further validate the relationship. Hence it is proposed that:

H1 Attitude has a significant influence on intention to exchange.

\section{Subjective norm and intention to exchange}

Subjective Norms (SBN), is referred as an individual's perceived societal pressures which forces or abstains an individual in performing a particular task or act [25]. Such societal pressures include influences from people who belong to an individual social circle, friends, family, mates and colleagues etc., which has a tendency to mold and frame an individual's aptitude [9]. In the context of studies discussing ecology and environment, SBN has been an important influencer in anticipating behavior [28]. Precisely, in the context of RL behavioral practices, despite of being a consistent determinant, its strength always changes. For instance, for recycling of plastics it was the highest TPB predictor of intention [5], so as for e-waste recycling [15], however, for reselling, donating and reusing it has generated contrasting results [11]. Nevertheless, these researchers advocates the importance and significance of SBN in predicting different intentions, therefore it is also assumed that it also generate the same level of significance in relationship for reverse exchange. Hence it is proposed that:

H2 Subjective Norms has a significant influence on intention to exchange.

\section{Perceived behavioral control and intention to exchange}

Perceived behavioral control (PBC), is referred as an individual's level of comfort and easiness while performing a particular task or act [25]. While comparing with the model of TPB and TRA, PBC was the phenomena which was added in the TPB based on its capability of determining intention [29]. According to Ajzen [25], the derivation of PBC is the outcome of two sub phenomena which are self-efficacy which is individual's intrinsic and the situational resources which dilutes the level of difficulty while performing a task or act. Nevertheless, the role of situational factors remain essential for an individual's intention and behavior [27]. In the context of studies discussing ecology and environment, $\mathrm{PBC}$ has remained consistent is terms of its predictability for behavioral intention, however, precisely for RL behavioral practices there is a dissimilarity among researchers. For instance, it is reported significant as the determinant of returning [16] and recycling [15] of e-waste, and donating and reselling plastics [11], however, for recycling plastics [5] and reusing plastics [11], it remains as negligible. This dissimilarity provide an enough evidence to explore the level of predictability for reverse exchange as well. Hence it is proposed that:

H3 Perceived Behavioral Control has a significant influence on intention to exchange.

\section{Moral Norms (MN) and intention to exchange}

MN is described as an individual's level of being morally and ethically concerned while performing a particular task or act. The importance of MN can also be understood by the acknowledgement that is made by the Ajzen [25] in terms of its propensity to predict behavioral intention. MN is regarded as a strong predictor for behavioral intention especially in the studies discussing ecology and environment [18] because of its nature of being moral and ethical consciousness. In the context of RL behavioral practices, for predicting the intention to return e-waste it was reported to be significant [16] whereas for recycling of the plastics 
its relationship was insignificant [5]. Precisely for reverse exchanges, it was studied as the predictor of ATT within the theoretical foundation of VBN which provides an avenue to predict it as the predictor of intention to exchange. Hence it is proposed that:

H4 Moral Norms has a significant influence on intention to exchange.

\section{Awareness of consequences $(\mathrm{AC})$ and intention to exchange}

$\mathrm{AC}$ is described as an individual's level of consciousness about the repercussions which may be caused due to the individual's act or abstinence. In the context of present study, an individual is said to be aware when he/she has the understanding about the repercussions to the ecology and environment due to his/her behavior [15]. In the context of $\mathrm{RL}, \mathrm{AC}$ has been regarded as the barrier which refrains an individual to act pro-environmentally hence organizations are advised to enhance the level of AC among the consumers [30]. Moreover, an individual with high level of AC is expected to return [16] and recycle [15] the e-waste, however, for reselling it is found insignificant [11]. Furthermore, for reverse exchanges, it was studied as the predictor of ATT within the theoretical foundation of VBN which provides an avenue to predict it as the predictor of intention to exchange. Hence it is proposed that:

H5 Awareness of consequences has a significant influence on intention to exchange.

\section{Intention to exchange and reversing behavior}

Intention which, according to the theoretical model of TRA and TPB, is an immediate predictor of behavior, has been stated as the individual's propensity to perform certain behavior [25]. An individual with the high level of propensity to act or abstinence is more likely to perform or refrain a particular behavior in actual [29]. Hence, for an individual to judge about his behavior can be possible when his intention is gauged. Moreover in the context of studies discussing ecology and environment, an intention was reported to predict waste separation among household [31], reducing the waste among construction workers [32], and donating [33]. Precisely, in the studies discussing RL behavior practice, it is also reported to have significant relationship when it comes to recycling [15] and returning [16] the e-waste, as well as reselling, disposing and reusing plastics [5]. Therefore it is also assumed that it also generates the same level of significance in relationship for reverse exchange. Hence it is proposed that:

H6 Intention to exchange has a significant influence on reverse behavior.

\section{Methodology}

In accordance with the problem highlighted in the present study, survey methodology is utilized in which quantitative data were collected from the respondents, which in present study are the consumer of the electronic products. Moreover, for data collection a research instrument was developed which is based on the adapted scales to measure the studied phenomena as summarized in Fig. 1. The sources of the studies from which the measuring scales are adapted are summarized in Table 1.

\section{Common method Variance (CMV)}

Though all of the questions were measured on the Likert scale of five points, however, there are certain procedural remedies [37] which was taken into account during the development of questionnaire, to control for CMV which
Fig. 1 Hypothesized framework of the present study

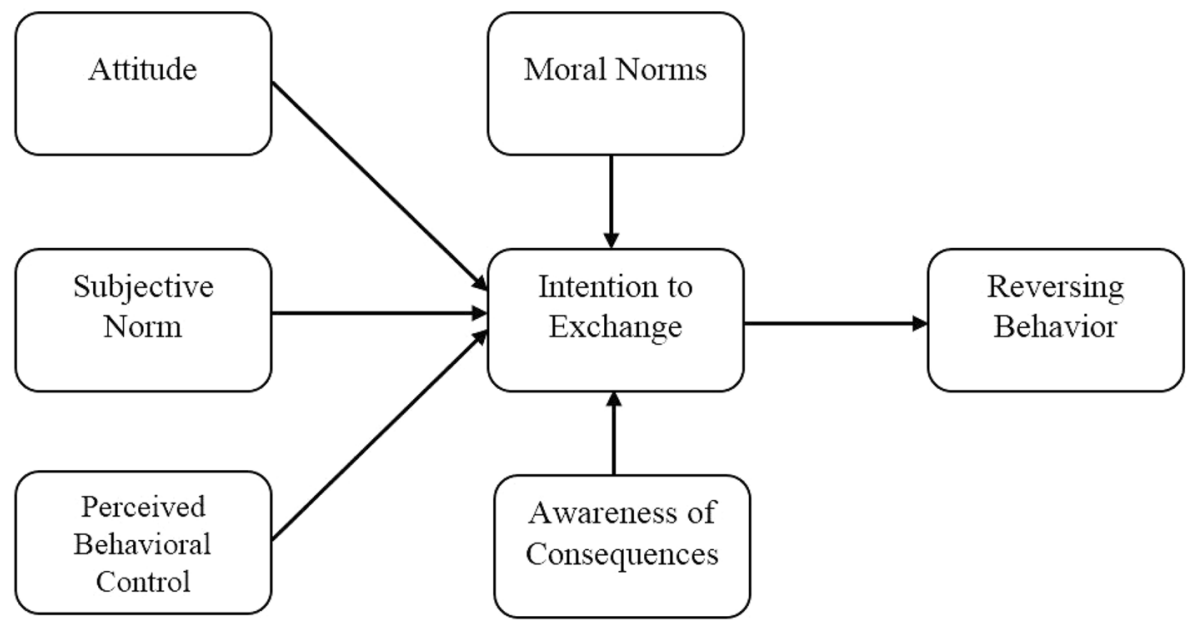


Table 1 Source of adaption of measuring items of the constructs

\begin{tabular}{ll}
\hline Constructs & References \\
\hline Reversing behavior & {$[27,34]$} \\
Intention to exchange & {$[13,18]$} \\
Awareness of consequences & {$[35]$} \\
Moral norms & {$[35]$} \\
Perceived behavioral control & {$[27,28]$} \\
Subjective norm & {$[28,36]$} \\
Attitude & {$[28,36]$} \\
\hline
\end{tabular}

is extremely crucial $[37,39]$. These includes the removal of the ambiguous statement, for which the assistance of the subject and language experts were obtained and their suggestions were accordingly incorporated. Secondly, the questions enquiring demographics were placed in-between the independent and dependent variables so that the respondents can have a temporal gap while transitioning from the questions of the one variable to another. Lastly, the statements of the independent variables were gauged on the scale of agreement ( 1 for Strongly Agree and 5 for Strongly Disagree) whereas dependent variables were gauged on the scale of possibility ( 1 for Definitely Not and 5 for Definitely). This change in scales will help the respondents in releasing of mental stress that they may came across while responding to the questions.

After the collection of data, statistical remedies were employed to evaluate the CMV. This includes the assessment by the help of Harman's [38] test. In this method, the generation of the factor were kept fixed at 1 during rotation and then the factors were generated of which the variation was assessed. Based on the Eigen values, the total generated factors explains the variation of $60.51 \%$ of which the first factor generated $19.9 \%$. These readings clearly shows the absence of CMV. On the other hand, the highest value of inter-construct correlations (exceeding 0.9) also indicates the presence of CMV [40,41] which is not the case in the present study (see Table 4). Hence all of the aforementioned measures employed confirms the absence of CMV and minimizes the possibilities of the biasness and inferiority in the estimations.

\section{Data collection method}

The mall interception method was used in which the data were collected when the consumers are leaving from the shopping malls after purchasing their desired electronic product. The reason for intercepting consumers at this point of time is the recent memory, which they had with respect to the disposing of the older product, for which they just made a replacement by purchasing a new product. Moreover, mall interception method has been regarded as the least biased and random which further helps in maintaining the anonymity of the consumers [42]. Therefore, based on the detailed operational recommendations by Sudman [43], the data were collected through mall interception.

\section{Comparing SEM VS ANN}

SEM is the regression based statistical technique which belongs to the group of second generation methods having capability of incorporating multiple dependent variables to be explained simultaneously. In addition to the benefits being offered by SEM there are certain limitations which mitigate the efficiency of predictability of SEM. Among them the most important is that SEM fails to capture the non-linear relationships among the variables [15]. Moreover, different types of SEM responds differently in the estimation and prediction. For instance, covariance based CBSEM generates inferior results when the data are not normal whereas Variance-based VB-SEM (e.g. PLS-SEM) explain more variation from data even if the size of the data is small and fails to meet the multivariate assumptions including normality while having outliers [5].

The aforementioned deficiencies can easily be addressed by ANN which is a technique established on artificial intelligence and has the similarity in working like human brain. Moreover, ANN operates in a manner where the development of knowledge is based on the regular learning from the data itself. In addition to this, the application of ANN involves training and testing whereby part of the data is used for training purpose, then the output is generated based on the said training and finally the generated output is compared with the actual output [45]. This process helps in generating more robust results and enhances the quality of prediction based on these predictions. Considering the multivariate assumptions, the ANN is reported to have least prone and the deficiency (if any) in meeting these assumptions does not affect the quality of predictions. Hence ANN is considered and known as the technique which has the capability to generate results with higher accuracy while comparing with the regression based techniques. Therefore, the present study applies the dual staged SEM-ANN approach to meet the research objectives of predicting determinants of human inclination towards reverse exchange. The comparison of CB-SEM, VB-SEM and ANN is graphical summarized by Henseler et al. [46] which is shown in Fig. 2.

In terms of improving the accuracy of predictions, the application of the dual staged SEM-ANN approach has been reported in several studies, for instance, acceptance for mobile payment [47], adopting mobile-government service [48] and consumer satisfaction in airline [49]. Precisely, in the context of RL and supply chain the application has been found in predicting sustainability by green supply chain practices [50], and predicting consumer contribution for 


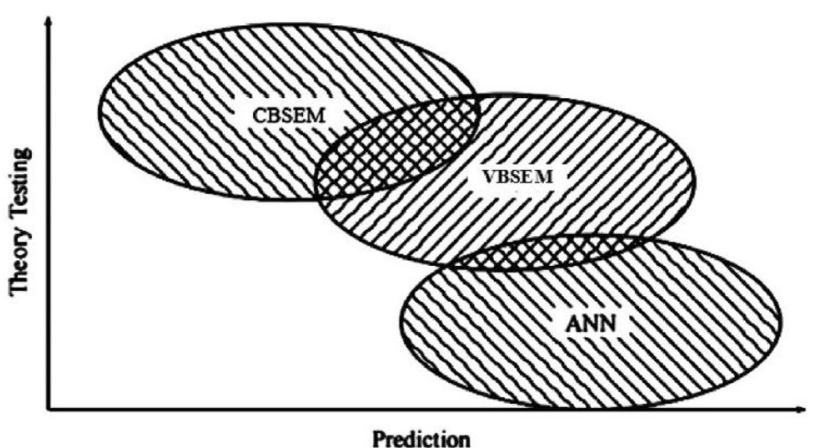

Fig. 2 Comparison of covariance-based structural equation modelling, variance based-structural equation modelling, and artificial neural network (Henseler et al. [46])

returning [16] and recycling [15] the e-waste. However, all of these applications were reported to implement single layer architecture which is considered as shallow architect [51]. Recently, this was also criticized by Lee et al. [19] whereas their study applied a deep learning dual layer architecture which further helps in the generation of more accurate and comprehensive outcome. Hence, based on the recommendations, the present study employed the deep learning double layered SEM-ANN approach, the results of which are further discussed in subsequent sections.

\section{Data preparation and screening}

Initially data from 1000 respondents were collected among which 254 responses were excluded during the stage of data screening and preparing the data for final estimations. The reasons for the exclusion of 254 responses includes: pattern filling (29 responses); incomplete (49 responses); respondents purchasing for the first time and do not have experience of disposing the older product (82 responses); univariate outliers (39 responses) and multivariate outliers (55 responses). Thus final data for estimating the proposed hypothesized relationships after data cleaning process comprised of 746 respondents. The demographics of the respondents are shown in Table 2.

\section{Data estimations and results}

The present study has utilized two software for the purpose of data analysis. Precisely in applying the deep learning double layered SEM-ANN approach, the initial data screening were performed by using SPSS, followed by the application of PLS-SEM which is done through SmartPLS whereas the ANN was also applied through SPSS. The detailed steps are discussed in subsequent sections.
Table 2 Demographic profiles of the respondents (sample $=746$ )

\begin{tabular}{lrr}
\hline Demographic & $N$ & Percentage $(\%)$ \\
\hline Gender & 490 & 66 \\
Male & 256 & 34 \\
Female & & \\
Education & 448 & 60 \\
Bachelors & 244 & 33 \\
Masters & 42 & 6 \\
Post-masters & 12 & 1 \\
Others & & \\
Age & 11 & 2 \\
Less than 18 years & 401 & 54 \\
18-24 years & 252 & 34 \\
25-30 years & 52 & 7 \\
31-35 years & 18 & 2 \\
36-40 years & 11 & 1 \\
41-50 years &
\end{tabular}

\section{Structural equation modelling}

As discussed, the present study has employed the VB category of SEM which is PLS-SEM. For the application, Hair et al. [44] has provided the detailed guidelines for the application of PLS-SEM which involves the two-stepped assessment. At first step, the outer model was assessed which includes the confirmation of convergent and discriminant validity followed by the assessment of inner model and hypotheses testing.

\section{Outer model}

As discussed, in this section the confirmation of convergent and discriminant validity were assured by the help of multiple parameters, as discussed below:

Convergent validity For a study having multiple variables and for which the data are collected in the same settings, it is pertinent to ensure the presence of convergent validity in the dataset. It has been explained as the level of relatedness that the measurements of one construct possess while comparing it with the measurements of another construct [52]. This tendency helps the items of a construct to group together accordingly and forming it statistically. In the present study, it has been assessed my multiple criteria summarized in Table 3.

Firstly, the assessment is done by factor loadings that need to be greater than 0.7 , secondly by Cronbach's Alpha and Composite Reliability $\backslash$ that also need to be greater than 0.7 and lastly by the value of Average Variance Extracted (AVE) which should be greater than 0.5. These threshold values are in accordance with the guidelines provided by 
Table 3 Assessment of convergent validity

\begin{tabular}{|c|c|c|c|c|c|}
\hline Constructs & Items & Factor loadings & $\begin{array}{l}\text { Cron- } \\
\text { bach's } \\
\text { Alpha }\end{array}$ & $\begin{array}{l}\text { Composite } \\
\text { reliability }\end{array}$ & $\begin{array}{l}\text { Average variance } \\
\text { extracted (AVE) }\end{array}$ \\
\hline \multirow[t]{4}{*}{ Awareness of consequences } & $\mathrm{AC} 2$ & 0.683 & \multirow[t]{4}{*}{0.711} & \multirow[t]{4}{*}{0.819} & \multirow[t]{4}{*}{0.532} \\
\hline & AC3 & 0.749 & & & \\
\hline & $\mathrm{AC} 4$ & 0.759 & & & \\
\hline & AC5 & 0.724 & & & \\
\hline \multirow[t]{5}{*}{ Attitude } & ATT1 & 0.794 & \multirow[t]{5}{*}{0.855} & \multirow[t]{5}{*}{0.896} & \multirow[t]{5}{*}{0.634} \\
\hline & ATT2 & 0.799 & & & \\
\hline & ATT3 & 0.837 & & & \\
\hline & ATT4 & 0.787 & & & \\
\hline & ATT5 & 0.761 & & & \\
\hline \multirow[t]{7}{*}{ Reversing behavior } & BEH1 & 0.739 & \multirow[t]{7}{*}{0.878} & \multirow[t]{7}{*}{0.900} & \multirow[t]{7}{*}{0.565} \\
\hline & $\mathrm{BEH} 2$ & 0.818 & & & \\
\hline & BEH3 & 0.820 & & & \\
\hline & BEH4 & 0.761 & & & \\
\hline & BEH5 & 0.727 & & & \\
\hline & BEH6 & 0.708 & & & \\
\hline & $\mathrm{BEH} 7$ & 0.676 & & & \\
\hline \multirow[t]{4}{*}{ Moral norms } & MN2 & 0.698 & \multirow[t]{4}{*}{0.688} & \multirow[t]{4}{*}{0.809} & \multirow[t]{4}{*}{0.515} \\
\hline & MN4 & 0.682 & & & \\
\hline & MN5 & 0.746 & & & \\
\hline & MN6 & 0.741 & & & \\
\hline \multirow[t]{5}{*}{ Perceived behavioral control } & $\mathrm{PBC} 2$ & 0.670 & \multirow[t]{5}{*}{0.819} & \multirow[t]{5}{*}{0.867} & \multirow[t]{5}{*}{0.567} \\
\hline & PBC3 & 0.762 & & & \\
\hline & $\mathrm{PBC} 4$ & 0.823 & & & \\
\hline & PBC5 & 0.733 & & & \\
\hline & PBC6 & 0.770 & & & \\
\hline \multirow[t]{5}{*}{ Subjective norm } & SN1 & 0.814 & \multirow[t]{5}{*}{0.842} & \multirow[t]{5}{*}{0.889} & \multirow[t]{5}{*}{0.618} \\
\hline & SN2 & 0.824 & & & \\
\hline & SN3 & 0.827 & & & \\
\hline & SN4 & 0.817 & & & \\
\hline & SN5 & 0.628 & & & \\
\hline \multirow[t]{5}{*}{ Intention to exchange } & EXH1 & 0.815 & \multirow[t]{5}{*}{0.888} & \multirow[t]{5}{*}{0.918} & \multirow[t]{5}{*}{0.691} \\
\hline & EXH2 & 0.862 & & & \\
\hline & EXH3 & 0.845 & & & \\
\hline & EXH4 & 0.850 & & & \\
\hline & EXH5 & 0.781 & & & \\
\hline
\end{tabular}

Hair et al. [44] and the results summarized in Table 3 confirms the meeting of the stated criteria.

Discriminant validity Similar to convergent validity, it is also crucial to assess discriminant validity when the data for multiple variables are collected in the same settings. Discriminant validity has been explained as the level of differentiation by which the measurements of one construct distinguished with the measurements of another construct [52]. This tendency helps the items of the constructs to have segregation and leading it to form different constructs statistically. The present study has assessed discriminant validity by three different criteria. Firstly by the Fornell-Larcker Criterion [53], according to which the level of differentiation among the constructs are determined when the square-root of AVE of a construct surpasses the values of the correlations that the same variable has with any other variable(s). The results of this criterion are shown in Table 4.

In Table 4, the bold values which are placed at diagonal represents the square-root of AVE, are found to be more than the values which are placed at off-diagonal places represents the inter-construct correlations. Thus the criterion proposed by Fornell-Larcker is satisfied. 
Table 4 Assessment of FornellLarcker Criterion

\begin{tabular}{llllllll}
\hline & AC & ATT & BEH & EXH & MN & PBC & SN \\
\hline AC & $\mathbf{0 . 7 2 9}$ & & & & & & \\
ATT & 0.460 & $\mathbf{0 . 7 9 6}$ & & & & & \\
BEH & 0.008 & 0.110 & $\mathbf{0 . 7 5 1}$ & & & & \\
EXH & 0.279 & 0.309 & 0.299 & $\mathbf{0 . 8 3 1}$ & & & \\
MN & 0.549 & 0.473 & 0.121 & 0.292 & $\mathbf{0 . 7 1 7}$ & & \\
PBC & 0.107 & 0.083 & 0.341 & 0.157 & 0.149 & $\mathbf{0 . 7 5 3}$ & \\
SN & 0.095 & 0.324 & 0.388 & 0.230 & 0.212 & 0.295 & $\mathbf{0 . 7 8 6}$ \\
\hline
\end{tabular}

Table 5 Assessment of Heterotrait-Monotrait Ratio (HTMT)

\begin{tabular}{llllllll}
\hline & AC & ATT & BEH & EXH & MN & PBC & SN \\
\hline AC & & & & & & \\
ATT & 0.574 & & & & & \\
BEH & 0.103 & 0.125 & & & & \\
EXH & 0.340 & 0.350 & 0.303 & & & \\
MN & 0.769 & 0.611 & 0.218 & 0.364 & & \\
PBC & 0.129 & 0.096 & 0.422 & 0.161 & 0.206 & 0.371 \\
SN & 0.144 & 0.373 & 0.459 & 0.260 & 0.279 & \\
\hline
\end{tabular}

The second criteria to assess discriminant validity is the new proposed heterotrait-monotrait (HTMT) ratio of correlations. This criteria emerged as the solution when the Fornell-Larcker Criterion [53] was largely criticized because of its inferiority and ineffectiveness [5]. For HTMT, the threshold value which satisfies the presence of discriminant validity is 0.85 [54], which is accordingly found in the present study as shown in Table 5.

\section{Inner model}

In this step, there is an assessment of the inner model of SEM which includes the predictability of the SEM model and hypotheses testing.

Predictive relevancy and accuracy For a model to be capable enough to predict appropriately and accurately, there are two measures which are widely used in the research involving SEM models. These includes coefficient of determination $\left(R^{2}\right)$, which shows the level of variation explanation in dependent variable by the independent variables. It is important to understand that $R^{2}$ is the function in which more independent variables lead to explain more variation in the dependent variable. Another measure to assess is crossvalidated redundancy $\left(Q^{2}\right)$, which is obtained by applying the procedure of blindfolding and need to be greater than 0 [44]. The results presented in Table 6 shows the satisfaction of the criteria.
Table 6 Assessment of Predictive power of constructs

\begin{tabular}{lll}
\hline & $R$ square & $Q$ square \\
\hline BEH & 0.089 & 0.041 \\
EXH & 0.155 & 0.098 \\
\hline
\end{tabular}

Hypotheses testing After meeting all of the quality parameters, the proposed hypotheses were finally tested. By employing the bootstrapping procedure, as suggested by Hair et al. [44] involving 5000 subsamples, the path coefficients which is the nature and strength of the relationship between variables and $p$-values which shows the significance of the relationships were estimated. The results of the estimations are shown in Table 7 and Fig. 3.

Based on the proposed hypotheses, all of them were reported to have significant relationships, however, there is a difference in terms of their strengths. For instance, for predicting intention to exchange, ATT of the individual was found to have high strength relationship which is 0.151. It means that, for an individual to have EXH, the ATT plays the most important role. The second strength in the relationship was found to be between $\mathrm{AC}$ and $\mathrm{EXH}$ which is 0.127 followed by $\mathrm{SN}$ and $\mathrm{MN}$ which is found to have the path coefficients of 0.122 and 0.113 , respectively. The weakest among the relationship was found between PBC and EXH which is 0.078. The significance of all of these relationships clearly show their role in making consumer motivated in their participation for reverse exchange of e-waste. The significance of the relationships is shown Fig. 4. 
Table 7 Hypotheses testing and estimations

\begin{tabular}{|c|c|c|c|c|c|c|}
\hline No. & Hypotheses & Path coefficient & SE & $\mathrm{T}$ statistics & $P$ Values & Remarks \\
\hline H1 & $\mathrm{ATT} \longrightarrow \mathrm{EXH}$ & 0.151 & 0.043 & 3.499 & 0.001 & Supported \\
\hline $\mathrm{H} 2$ & $\mathrm{SN} \longrightarrow \mathrm{EXH}$ & 0.122 & 0.034 & 3.604 & 0.000 & Supported \\
\hline H3 & $\mathrm{PBC} \longrightarrow \mathrm{EXH}$ & 0.078 & 0.033 & 2.376 & 0.018 & Supported \\
\hline H4 & $\mathrm{MN} \longrightarrow \mathrm{EXH}$ & 0.113 & 0.044 & 2.551 & 0.011 & Supported \\
\hline H5 & $\mathrm{AC} \longrightarrow \mathrm{EXH}$ & 0.127 & 0.041 & 3.089 & 0.002 & Supported \\
\hline H6 & $\mathrm{EXH} \longrightarrow \mathrm{BEH}$ & 0.299 & 0.035 & 8.574 & 0.000 & Supported \\
\hline
\end{tabular}

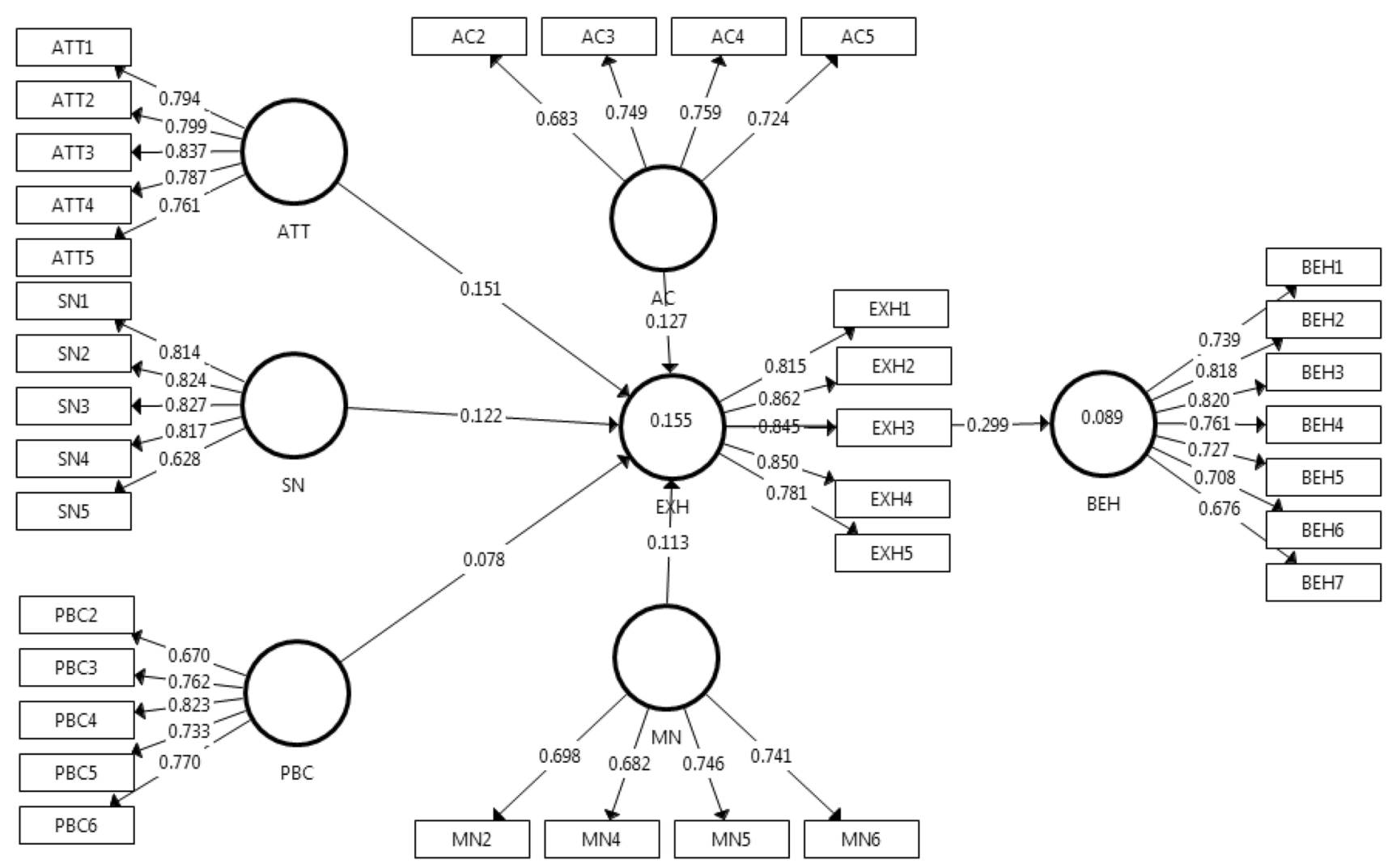

Fig. 3 Results of partial least square—-structural equation modelling algorithm

\section{Artificial neural network}

The present study employed the deep learning architect of ANN as suggested by Lee et al. [19] which contains dual layers and is helpful in providing in-depth results from the estimations. Lee et al. [19] consider typical ANN utilized in the studies having SEM-ANN as shallow, hence based on the suggestions, a deeper ANN is applied. Precisely, it was the application of multi-layer perceptron which is comprised of three layers namely inputs, hidden and output layers, whereby all of the layers are connected by synaptic weights. Through the activation of non-linear function, the flow of the data moves around neuron nodes from input to hidden where learning is developed and then from hidden to outputs. Moreover sigmoid function was selected as the ANN architect function with the relaxation in terms of generating hidden neurons automatically, whereas $90 \%$ of the data were kept for training and remaining were used as testing of which the error was computed. Lastly, the procedure incorporates 10 -fold cross-validation which helps in reducing the possibility of over fitting of the ANN. In addition to this, Root Mean Square Error (RMSE) is calculated for evaluating the quality of the prediction whereas sensitivity analysis was performed to evaluate average importance of the inputs which is similar to the path coefficients of any regression model.

In accordance with the framework proposed in Fig. 1, there are two models of ANN which was performed as per the guidelines. The first model has EXH as dependent 


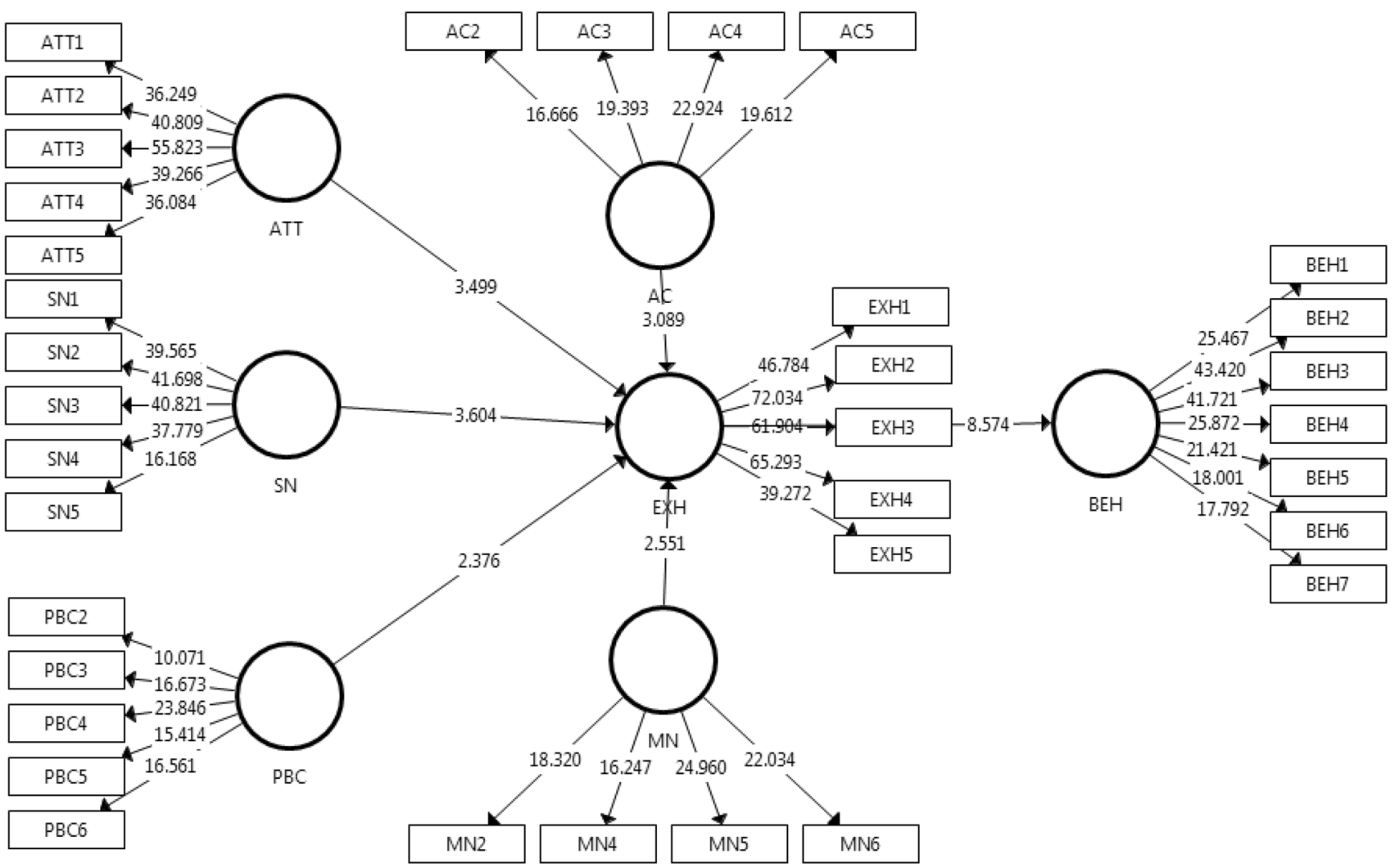

Fig. 4 Results of significance of partial least square—structural equation modelling

variable (refer Fig. 5) whereas second model has BEH as dependent variable (refer Fig. 6).

The summary of the application of the ANN after tenfold cross-validation revealed an RMSE value of 0.128 and 0.130 for training and testing, respectively for Model 1 having ATT, SN, PBC, MN, AC as inputs and RMSE value of 0.151 and 0.140 for training and testing, respectively for Model 2 having EXH as input. The values of RMSE are found to be quite low which are in normally found in other related studies. The results of all the ANN for both the models and their RMSE values for training and testing, respectively are shown in Table 8 .

The application of the sensitivity analysis helps in computing the relative importance of all the inputs against their outputs which are similar to the path coefficients of the PLS model. According to the results of ANN, the highest input for predicting EXH is found as ATT followed by AC and MN with $91.16 \%$ and $90.80 \%$ importance, whereas SN and $\mathrm{PBC}$ were found to have $76.29 \%$ and $43.39 \%$ importance, respectively. The findings from the sensitivity analysis are shown in Table 9.

\section{Comparison of PLS-SEM and ANN}

While comparing the results of PLS-SEM and ANN, based on the path coefficients from PLS-SEM and relative importance of the inputs for outputs from ANN, most of the findings are found to be similar. Referring Table 10, ATT remains the highest important predictor followed by AC, whereas PBC remains the weakest while comparing the results of both the analysis. Considering the norms, PLSSEM reported to have SN as the third important whereas as per the findings of ANN it is at fourth place and same is the case of MN. These differences are because of the capability of capturing non-linear relationships whereas ANN tends to explain more variation from the data [55]. Hence the difference in the importance of relationships is because of application of deep learning dual staged PLSSEM-ANN which could have been missed if only PLSSEM is applied on the dataset. The comparison of the analysis is shown in Table 10 . 


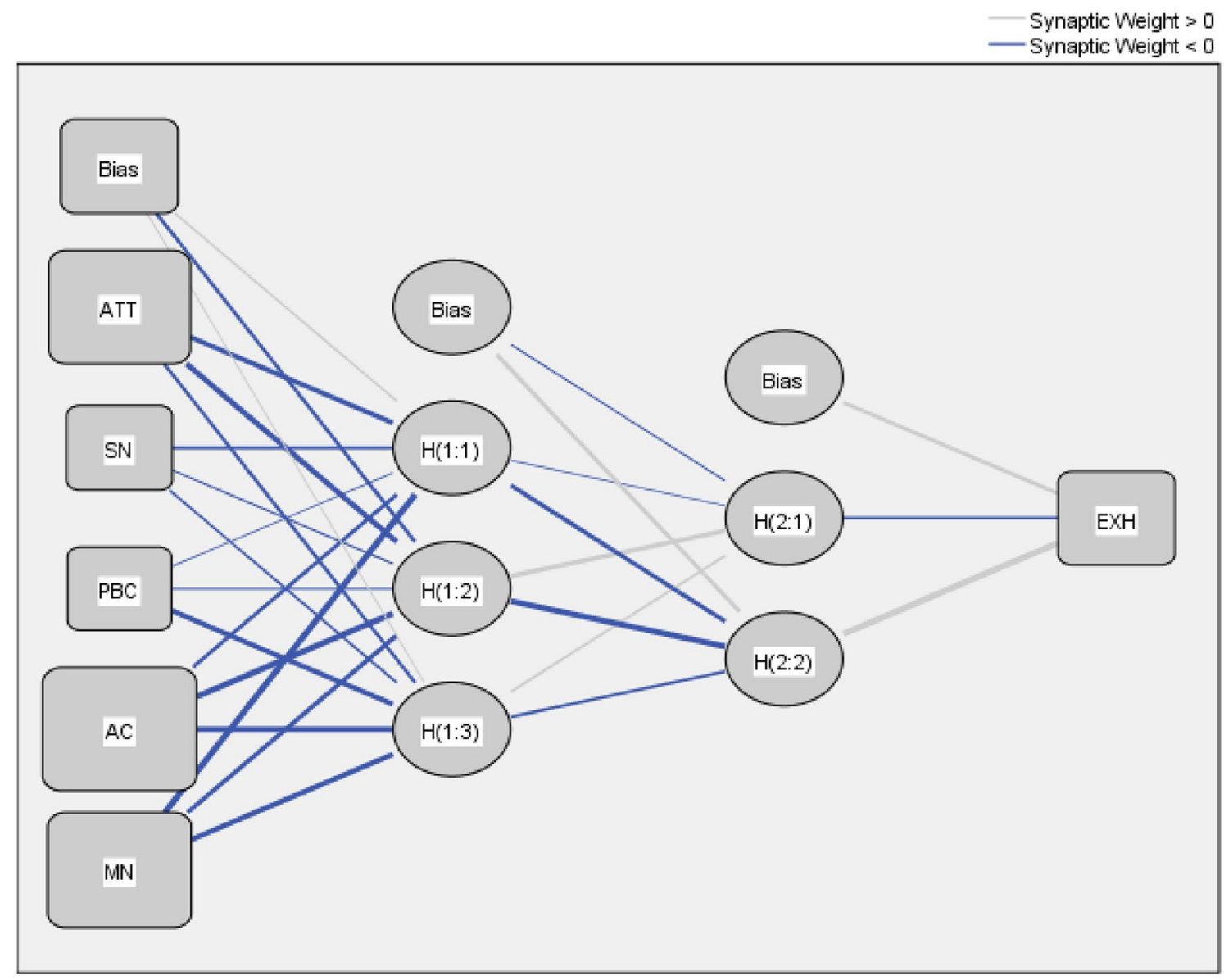

Hidden layer activation function: Sigmoid

Output layer activation function: Sigmoid

Fig. 5 Output of Artificial Neural Network Model 1

\section{Discussion}

Reverse exchange being a reversing behavioral practice by consumer in the context of RL for the purpose of conserving the resources is a least studied phenomena. For a manufacturer, it is a sustainable practice to call back the EOL products which helps them in achieving financial, environmental and social excellence. However, engagement from the consumer side is of significant importance. The findings of the present study, also provide empirical justification in the support of the hypotheses proposed.

The findings reported all of the hypotheses as significant and important. Precisely, ATT was found to be extremely important predictor in the present study. It means to make a consumer exchange the product at the EOL stage, it is important to develop his ATT. Though ATT of an individual is an intrinsic response, however, this response is, and can be, triggered by various external forces. Hence manufacturer can use this cue to get engagement from the consumers in their decision towards reverse exchange. This is also the case of the other constructs of TPB which are SN and PBC. These findings have the similarity with other RL based researches like recycle [15] and return [16], however, having similar results in the context of exchange is the potential contribution of the present study.

On the other hand, the constructs of $\mathrm{AC}$ and $\mathrm{MN}$ also reported to be significant. This means that a consumer who are morally concerned and had a knowledge and understanding regarding the consequences and environment repercussions, are more likely to engage in the reverse exchange. These findings are supported by the results in the context of plastics [5] and e-waste [15] recycling. Hence manufacturers, based on the findings, can strategize the operations for incorporating the reverse exchange and accordingly increase the consumer engagement and participation. 


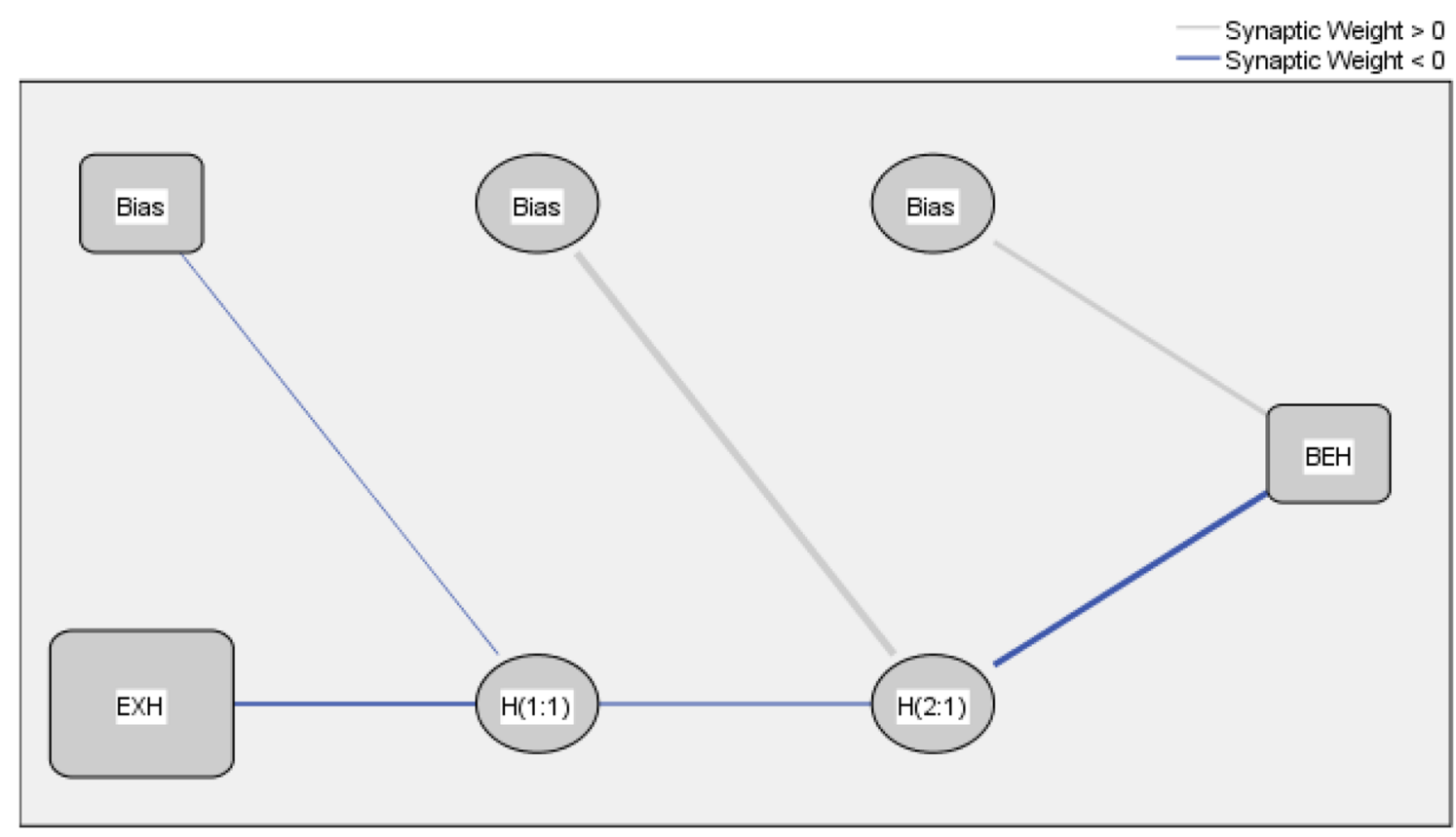

Hidden layer activation function: Sigmoid

Output layer activation function: Sigmoid

Fig. 6 Output of Artificial Neural Network Model 2

Table 8 Root mean square error values

\begin{tabular}{|c|c|c|c|c|c|c|c|c|c|c|c|c|}
\hline \multicolumn{4}{|c|}{ Model 1: training } & \multicolumn{3}{|c|}{ Model 1: testing } & \multicolumn{3}{|c|}{ Model 2: training } & \multicolumn{3}{|c|}{ Model 2: testing } \\
\hline & $N$ & SSE & RMSE & $N$ & SSE & RMSE & $N$ & SSE & RMSE & $N$ & SSE & RMSE \\
\hline ANN1 & 663 & 11.169 & 0.130 & 83 & 0.975 & 0.108 & 676 & 16.468 & 0.156 & 70 & 1.545 & 0.149 \\
\hline ANN2 & 659 & 10.688 & 0.127 & 87 & 1.423 & 0.128 & 665 & 14.906 & 0.150 & 81 & 1.750 & 0.147 \\
\hline ANN3 & 667 & 10.620 & 0.126 & 79 & 1.049 & 0.115 & 687 & 17.071 & 0.158 & 59 & 1.087 & 0.136 \\
\hline ANN4 & 674 & 11.401 & 0.130 & 72 & 1.178 & 0.128 & 674 & 15.170 & 0.150 & 72 & 1.351 & 0.137 \\
\hline ANN5 & 669 & 11.015 & 0.128 & 77 & 1.468 & 0.138 & 658 & 15.050 & 0.151 & 88 & 1.587 & 0.134 \\
\hline ANN6 & 668 & 10.614 & 0.126 & 78 & 1.470 & 0.137 & 684 & 15.098 & 0.149 & 62 & 1.410 & 0.151 \\
\hline ANN7 & 667 & 10.468 & 0.125 & 79 & 1.641 & 0.144 & 663 & 14.565 & 0.148 & 83 & 1.939 & 0.153 \\
\hline ANN8 & 665 & 10.543 & 0.126 & 81 & 1.775 & 0.148 & 672 & 15.192 & 0.150 & 74 & 1.372 & 0.136 \\
\hline ANN9 & 672 & 11.222 & 0.129 & 74 & 1.354 & 0.135 & 666 & 15.036 & 0.150 & 80 & 1.469 & 0.136 \\
\hline \multirow[t]{3}{*}{ ANN10 } & 658 & 10.689 & 0.127 & 88 & 1.321 & 0.123 & 672 & 15.492 & 0.152 & 74 & 1.081 & 0.121 \\
\hline & & MEAN & 0.128 & & MEAN & 0.130 & & MEAN & 0.151 & & MEAN & 0.140 \\
\hline & & SD & 0.002 & & SD & 0.013 & & SD & 0.003 & & SD & 0.010 \\
\hline
\end{tabular}

\section{Conclusion and recommendations}

The pandemic of COVID 19 has disrupted every human life by putting the global activities at halt. People while staying at home tend to have an increased consumption which also leads to an increased level of waste generation. In such a situation, where there is a continuous generation of waste and lesser collection and disposing, there is a need to have a sense of sustainable consumption among the consumers so that their consumption does not lead to ecological deterioration. The case of e-waste is also not different in terms of its collection, however, it has severe repercussions while comparing it with other general household waste. Therefore, consumers should also be diligent and prudent in disposing the EOL waste.

The application of RL by the manufacturers though serve the purpose but its success is highly dependent on the participation of the consumers. The participation of the consumers can be gauged by the level of returning, disposing, recycling 
Table 9 Sensitivity analysis

\begin{tabular}{|c|c|c|c|c|c|c|}
\hline \multicolumn{6}{|l|}{ Model 1: Output $=\mathrm{EXH}$} & \multirow{2}{*}{$\begin{array}{l}\text { Model } \\
2: \text { Out- } \\
\text { put }=\text { BEH } \\
\text { EXH }\end{array}$} \\
\hline & ATT & $\mathrm{SN}$ & PBC & $\mathrm{AC}$ & $\mathrm{MN}$ & \\
\hline ANN1 & 0.217 & 0.177 & 0.130 & 0.204 & 0.273 & 1 \\
\hline ANN2 & 0.281 & 0.192 & 0.107 & 0.229 & 0.191 & 1 \\
\hline ANN3 & 0.256 & 0.225 & 0.126 & 0.239 & 0.153 & 1 \\
\hline ANN4 & 0.319 & 0.196 & 0.016 & 0.149 & 0.320 & 1 \\
\hline ANN5 & 0.187 & 0.185 & 0.099 & 0.331 & 0.198 & 1 \\
\hline ANN6 & 0.260 & 0.247 & 0.134 & 0.187 & 0.171 & 1 \\
\hline ANN7 & 0.280 & 0.207 & 0.129 & 0.204 & 0.180 & 1 \\
\hline ANN8 & 0.247 & 0.103 & 0.095 & 0.298 & 0.256 & 1 \\
\hline ANN9 & 0.216 & 0.173 & 0.132 & 0.198 & 0.281 & 1 \\
\hline ANN10 & 0.226 & 0.194 & 0.112 & 0.230 & 0.237 & 1 \\
\hline Average importance & 0.249 & 0.190 & 0.108 & 0.227 & 0.226 & 1 \\
\hline Normalized importance (\%) & 100 & 76.296 & 43.391 & 91.161 & 90.800 & 100 \\
\hline
\end{tabular}

Table 10 Comparing the results of PLS-SEM and ANN $($ dependent variable $=\mathrm{EXH})$

\begin{tabular}{|c|c|c|c|c|c|c|}
\hline \multirow{2}{*}{$\begin{array}{l}\text { Independent } \\
\text { variables }\end{array}$} & \multicolumn{3}{|l|}{ PLS-SEM } & \multicolumn{2}{|l|}{ ANN } & \multirow[t]{2}{*}{ Remarks } \\
\hline & Path coefficients & Results & $\begin{array}{l}\text { Ranking as per } \\
\text { path coefficients }\end{array}$ & Ranking & $\begin{array}{l}\text { Normalized } \\
\text { importance }(\%)\end{array}$ & \\
\hline ATT & 0.151 & Significant & 1 & 1 & 100 & Matched \\
\hline $\mathrm{AC}$ & 0.127 & Significant & 2 & 2 & 91.161 & Matched \\
\hline SN & 0.122 & Significant & 3 & 4 & 76.296 & \\
\hline MN & 0.113 & Significant & 4 & 3 & 90.800 & \\
\hline PBC & 0.078 & Significant & 5 & 5 & 43.391 & Matched \\
\hline
\end{tabular}

and reselling the e-waste, however, among these the participating by exchanging could lead to a more sustainable solution for all of the stakeholders as it helps in disposing of the EOL products more systematically. Hence present study is an attempt to address the objective of gauging the level of participation from the consumers in the reverse exchange programs for e-waste.

Because of the predictability limitations of the typical SEM models, the present study employs the deep learning of the dual-staged PLS-SEM-ANN approach. The findings of the study confirms the attitude of the individual as the most significant determinant of the intention to exchange, followed by a level of awareness and norms whereas PBC was found to be least important though significant. Based on the findings, the present study offers certain implications and recommendations which are discussed in the subsequent sections.

\section{Recommendations}

Based on the findings, the present study offers various policy recommendations. Firstly, manufacturers need to have the incorporation of reverse exchange program in their product offering for its EOL stage. This will help the manufacturers not just in retaining and increasing the customer base but also in retrieving the precious components which can be reused with little or no re-manufacturing. Secondly, manufacturers need to be appropriate marketing campaigns by which awareness among the consumers can be increased which will also create motivation among the consumers for participating in the reverse programs. Such advertising and campaigns will also help in molding the societal norms where participation in reverse programs are encouraged. Thirdly, manufacturers need to have the placement of proper RL infrastructure which will provide assistance to the consumers in their reversing behavior. Fourthly, in a situation where consumers are not willing to purchase the product from the same manufacturer, an offering of financial incentives as an honorarium for the reversing the EOL product could also be a good alternative which will create a win-win situation for both manufactures and consumers.

In addition to aforementioned recommendations, there is a need to have government interventions. Such interventions can include (but should not be limited to): legislations related to ecology and waste management by which governance of waste can be improved; compliance to the legislations by the parties by which their respective participation is ensured; provision of infrastructural support and encouragement of public-private 
partnerships for the sustainable resolution to this problem; are few to be mentioned.

\section{Limitations and directions for future research}

Despite the potential contributions made by the present study, there are certain limitation on which the future directions are also recommended. Firstly, the present study employs a deep learning dual staged PLS-SEM-ANN which is considered as comparatively better than conventional shallow ANN, however, researchers are advised to validate the argument by employing it on different datasets. Moreover, a comparisonbased research is also recommended in which the differences in the results are discussed and highlighted. Secondly, the present study lacks the incorporation of certain situational factors as moderators which according to Fishbein and Azjen [29] are essential in transforming intention into behavior. Thirdly, the present study is based on the perceived behavioral practices of the individuals as per the theoretical foundations of TPB and hence there is a need to have a study that discusses the actual behavior of the individual(s). Lastly, the present study is focused on the practice of reverse exchange only whereas a detailed exploration is required, in which similar consumers' RL behavioral practices are identified and accordingly studied.

Author contributions AN: conceptualization, literature review, data collection, data analysis, write-up. KK: conceptualization, write-up, editing, reviewing. AA: conceptualization, write-up, editing, reviewing. All the authors read and approved the final manuscript.

Funding This research study did not receive any funding.

Availability of data and materials All the data analysis results and tools/models used in this study are included in this article.

\section{Declarations}

Conflict of interests The authors declare that they have no conflict of interest.

Ethical approval Official approval was taken from the ethics committee of the University of Malaya.

Consent to participate Consent was obtained from the participants prior to data collection.

Consent to publish Consent was obtained from the participants prior to data collection, whereas no respondent was individually identified in this study.

\section{References}

1. Chakraborty I, Maity P (2020) COVID-19 outbreak: migration, effects on society, global environment and prevention. Sci Total Environ 728:138882
2. Sharma HB, Vanapalli KR, Cheela VS, Ranjan VP, Jaglan AK, Dubey B et al (2020) Challenges, opportunities, and innovations for effective solid waste management during and post COVID-19 pandemic. Resour Conserv Recycl 162:105052

3. Sarkodie SA, Owusu PA (2020) Impact of COVID-19 pandemic on waste management. Environ Dev Sustain 23:1-10

4. Sadrnia A, Langarudi NR, Sani AP (2020) Logistics network design to reuse second-hand household appliances for charities. J Clean Prod 244:118717

5. Khan F, Ahmed W, Najmi A (2019) Understanding consumers' behavior intentions towards dealing with the plastic waste: perspective of a developing country. Resour Conserv Recycl 142:49-58

6. Tran VCM, Le HS, Matsui Y (2019) Current status and behavior modeling on household solid-waste separation: a case study in Da Nang city, Vietnam. J Mater Cycles Waste Manag 21(6):1462-1476

7. Ghalehkhondabi I, Ardjmand E (2020) Sustainable e-waste supply chain management with price/sustainability-sensitive demand and government intervention. J Mater Cycles Waste Manag 22(2):556-577

8. Arshadi M, Yaghmaei S, Esmaeili A (2020) Evaluating the optimal digestion method and value distribution of precious metals from different waste printed circuit boards. J Mater Cycles Waste Manag 22(5):1690-1698

9. Najmi A, Kanapathy K, Aziz AA (2019) Prioritising factors influencing consumers' reversing intention of e-waste using analytic hierarchy process. Int J Electron Cust Relationsh Manag 12(1):58-74

10. Forti V, Baldé CP, Kuehr R, Bel G (2020) The global e-waste monitor 2020: quantities, flows and the circular economy potential. United Nations University (UNU), Bonn

11. Khan F, Ahmed W, Najmi A, Younus M (2019) Managing plastic waste disposal by assessing consumers' recycling behavior: the case of a densely populated developing country. Environ Sci Pollut Res 26(32):33054-33066

12. Johnson PF (1998) Managing value in reverse logistics systems. Transport Res E Log 34(3):217-227

13. Jena SK, Sarmah S (2015) Measurement of consumers' return intention index towards returning the used products. J Clean Prod 108:818-829

14. Theis N (2020) The global trade in e-waste: a network approach. Environ Sociol 7:1-14

15. Najmi A, Kanapathy K, Aziz AA (2020) Exploring consumer participation in environment management: findings from two-staged structural equation modelling-artificial neural network approach. Corp Soc Responsib Environ Manag 28:184-195

16. Najmi A, Kanapathy K, Aziz AA (2020) Understanding consumer participation in managing ICT waste: findings from two-staged structural equation modeling-Artificial Neural Network approach. Environ Sci Pollut Res 28:1-15

17. Prakash C, Barua MK, Pandya KV (2015) Barriers analysis for reverse logistics implementation in Indian electronics industry using fuzzy analytic hierarchy process. Proc Soc Behav Sci 189:91-102

18. Yuan R, Liu MJ, Chong AY-L, Tan KH (2016) An empirical analysis of consumer motivation towards reverse exchange. Supply Chain Manag 21(2):180-193

19. Lee VH, Hew JJ, Leong LY, Tan GWH, Ooi KB (2020) Wearable payment: a deep learning-based dual-stage SEM-ANN analysis. Expert Syst Appl 157:113477

20. Ajzen I (1985) From intentions to actions: a theory of planned behaviour. Action control. Springer, Berlin, pp 11-39

21. Fishbein M, Ajzen I (1975) Belief. Attitude, intention and behavior: an introduction to theory and research. Addison-Wesley Publishing Company, p 578 
22. Stern PC (2000) Toward a coherent theory of environmentally significant behavior. J Soc Issues 56(3):407-424

23. Schwartz SH (1977) Normative influences on altruism. Adv Exp Soc Psychol 10:221-279

24. Wan C, Shen GQ, Yu A (2014) The role of perceived effectiveness of policy measures in predicting recycling behaviour in Hong Kong. Resour Conserv Recycl 83:141-151

25. Ajzen I (1991) The theory of planned behavior. Organ Behav Hum Decis Process 50(2):179-211

26. Khor KS, Hazen BT (2017) Remanufactured products purchase intentions and behaviour: evidence from Malaysia. Int J Prod Res 55(8):2149-2162

27. Dixit S, Badgaiyan AJ (2016) Towards improved understanding of reverse logistics-examining mediating role of return intention. Resour Conserv Recycl 107:115-128

28. Kianpour K, Jusoh A, Mardani A, Streimikiene D, Cavallaro F, Nor KM, Zavadskas EK (2017) Factors influencing consumers' intention to return the end of life electronic products through reverse supply chain management for reuse, repair and recycling. Sustainability 9(9):1657

29. Fishbein M, Ajzen I (2011) Predicting and changing behavior: the reasoned action approach. Taylor \& Francis, New York

30. Abdulrahman MD, Gunasekaran A, Subramanian N (2014) Critical barriers in implementing reverse logistics in the Chinese manufacturing sectors. Int J Prod Econ 147:460-471

31. Xu L, Ling M, Lu Y, Shen M (2017) External influences on forming residents' waste separation behaviour: evidence from households in Hangzhou, China. Habitat Int 63:21-33

32. Li J, Zuo J, Cai H, Zillante G (2018) Construction waste reduction behavior of contractor employees: an extended theory of planned behavior model approach. J Clean Prod 172:1399-1408

33. Morgan LR, Birtwistle G (2009) An investigation of young fashion consumers' disposal habits. Int J Consum Stud 33(2):190-198

34. Ahmad MS, Bazmi AA, Bhutto AW, Shahzadi K, Bukhari N (2016) Students' responses to improve environmental sustainability through recycling: quantitatively improving qualitative model. Appl Res Qual Life 11(1):253-270

35. Jansson J, Marell A, Nordlund A (2011) Exploring consumer adoption of a high involvement eco-innovation using value-beliefnorm theory. J Consum Behav 10(1):51-60

36. Tonglet M, Phillips PS, Read AD (2004) Using the theory of planned behaviour to investigate the determinants of recycling behaviour: a case study from Brixworth, UK. Resour Conserv Recycl 41(3):191-214

37. Podsakoff PM, MacKenzie SB, Podsakoff NP (2012) Sources of method bias in social science research and recommendations on how to control it. Annu Rev Psychol 63:539-569

38. Harman HH (1967) Modem factor analysis. University of Chicago, Chicago

39. Podsakoff PM, MacKenzie SB, Lee JY, Podsakoff NP (2003) Common method biases in behavioral research: a critical review of the literature and recommended remedies. J Appl Psychol 88(5):879

40. Najmi A, Ahmed W (2018) Assessing channel quality to measure customers' outcome in online purchasing. Int J Electron Cust Relationsh Manag 11(2):179-201

41. Ali F, Kim WG, Ryu K (2016) The effect of physical environment on passenger delight and satisfaction: moderating effect of national identity. Tour Manag 57:213-224
42. Khare A (2014) Consumers' susceptibility to interpersonal influence as a determining factor of ecologically conscious behaviour. Mark Intell Plan 32(1):2-20

43. Sudman $S$ (1980) Improving the quality of shopping center sampling. J Mark Res 17(4):423-431

44. Hair JF, Hult GTM, Christian MR, Sarstedt M (2017) A primer on partial least squares structural equation modeling (PLS-SEM). Sage, Thousand Oaks

45. Hew JJ, Leong LY, Tan GWH, Ooi KB, Lee VH (2019) The age of mobile social commerce: an artificial neural network analysis on its resistances. Technol Forecast Soc Chang 144:311-324

46. Henseler J, Ringle CM, Sinkovics RR (2009) The use of partial least squares path modeling in international marketing. In: Sinkovics RR, Ghauri PN (eds) New challenges to international marketing, vol 20. Emerald Group Publishing Limited, Bingley, pp 277-319. https://doi.org/10.1108/S1474-7979(2009)0000020014

47. Kalinic Z, Marinkovic V, Molinillo S, Liebana-Cabanillas F (2019) A multi-analytical approach to peer-to-peer mobile payment acceptance prediction. J Retail Consum Serv 49:143-153

48. Talukder S, Chiong R, Dhakal S, Sorwar G, Bao Y (2019) A twostage structural equation modeling-neural network approach for understanding and predicting the determinants of m-government service adoption. J Syst Inf Technol 21:419-438

49. Leong LY, Hew TS, Lee VH, Ooi KB (2015) An SEM-artificialneural-network analysis of the relationships between SERVPERF, customer satisfaction and loyalty among low-cost and full-service airline. Expert Syst Appl 42(19):6620-6634

50. Foo PY, Lee VH, Tan GWH, Ooi KB (2018) A gateway to realising sustainability performance via green supply chain management practices: a PLS-ANN approach. Expert Syst Appl 107:1-14

51. Huang W, Stokes JW (2016) MtNet: a multi-task neural network for dynamic malware classification. In: International conference on detection of intrusions and malware, and vulnerability assessment, Springer, Cham, pp 399-418

52. Mehmood SM, Najmi A (2017) Understanding the impact of service convenience on customer satisfaction in home delivery: evidence from Pakistan. Int J Electron Cust Relationsh Manag 11(1):23-43

53. Fornell C, Larcker DF (1981) Evaluating structural equation models with unobservable variables and measurement error. J Mark Res 18(1):39-50

54. Henseler J, Ringle CM, Sarstedt M (2015) A new criterion for assessing discriminant validity in variance-based structural equation modeling. J Acad Mark Sci 43(1):115-135

55. Oparaji U, Sheu RJ, Bankhead M, Austin J, Patelli E (2017) Robust artificial neural network for reliability and sensitivity analyses of complex non-linear systems. Neural Netw 96:80-90

Publisher's Note Springer Nature remains neutral with regard to jurisdictional claims in published maps and institutional affiliations. 